ISSN 1420-3049

www.mdpi.com/journal/molecules

Article

\title{
Antiparasitic Activity of Natural and Semi-Synthetic Tirucallane Triterpenoids from Schinus terebinthifolius (Anacardiaceae): Structure/Activity Relationships
}

Thiago R. Morais ${ }^{1}$, Thais A. da Costa-Silva ${ }^{2}$, Andre G. Tempone ${ }^{2}$, Samanta Etel T. Borborema ${ }^{2}$, Marcus T. Scotti ${ }^{3}$, Raquel Maria F. de Sousa ${ }^{4}$, Ana Carolina C. Araujo ${ }^{4}$, Alberto de Oliveira ${ }^{4}$, Sérgio Antônio L. de Morais ${ }^{4}$, Patricia Sartorelli ${ }^{1}$ and João Henrique G. Lago ${ }^{1}$ **

1 Instituto de Ciências Ambientais, Químicas e Farmacêuticas, Universidade Federal de São Paulo, Diadema, SP 09972270, Brazil

2 Centro de Parasitologia, Instituto Adolfo Lutz, São Paulo, SP 01246902, Brazil

3 Centro de Ciências Aplicadas e Educação, Universidade Federal da Paraíba, Rio Tinto, PB 58297000, Brazil

4 Instituto de Química, Universidade Federal de Uberlândia, Uberlândia, MG 38400902, Brazil

* Author to whom correspondence should be addressed; E-Mail: joao.lago@unifesp.br; Tel.: +55-11-3319-3300; Fax: +55-11-4043-6428.

Received: 12 March 2014; in revised form: 26 April 2014 / Accepted: 28 April 2014 / Published: 5 May 2014

\begin{abstract}
Leishmaniasis and Chagas are diseases caused by parasitic protozoans that affect the poorest population in the World, causing a high mortality and morbidity. As a result of highly toxic and long-term treatments, the discovery of novel, safe and more efficacious drugs is essential. In this work, the in vitro antiparasitic activity and mammalian cytotoxicity of three natural tirucallane triterpenoids, isolated from leaves of Schinus terebinthifolius (Anacardiaceae), and nine semi-synthetic derivatives were investigated against Leishmania (L.) infantum and Trypanosoma cruzi. Trypomastigotes of T. cruzi were the most susceptible parasites and seven compounds demonstrated a trypanocidal activity with $\mathrm{IC}_{50}$ values in the range between 15 and $58 \mu \mathrm{g} / \mathrm{mL}$. Four compounds demonstrated selectivity towards the intracellular amastigotes of Leishmania, with $\mathrm{IC}_{50}$ values in the range between 28 and $97 \mu \mathrm{g} / \mathrm{mL}$. The complete characterization of triterpenoids was afforded after thorough analysis of nuclear magnetic resonance (NMR) data as well as electrospray ionization mass spectrometry (ESI-MS). Additionally, structure-activity relationships were performed using Decision Trees.
\end{abstract}


Keywords: Schinus terebinthifolius; leaves; tirucallane triterpenoids; Leishmania (L.) infantum; Trypanosoma cruzi; structure-activity

\section{Introduction}

Specimens of Schinus terebinthifolius, known in Brazil as "aroeira-vermelha" or "aroeira-pimenteira", are large trees that can reach $40 \mathrm{~m}$ height and $1-3 \mathrm{~m}$ in diameter [1,2]. In folk medicine, this plant has been used to treat ulcers, respiratory problems, wounds, rheumatism, gout, diarrhea, skin disease and arthritis, as well as antiseptic and anti-inflammatory [3]. In addition, decoctions of flowers, stems, leaves and fruits are used for the treatment of tumors and hanseniasis [4].

Previous chemical studies with leaves extracts of $S$. terebinthifolius have been carried out and fatty acids and terpenoids were isolated, especially tirucallane derivatives (masticadienoic acid and schinol) which have shown inhibitory activity on phospholipase A2 [5] and antifungal potential against Paracoccidioides brasiliensis [6]. Other compounds, such as phenolic derivatives (gallic acid, methyl and ethyl gallates) and flavonoids (trans-catechin, kaempferol, quercitrin, afzelin, myricetin, and myricetrin) were also isolated from the leaves and displayed antiradical and cytotoxic activities [7,8]. Chemical analysis of barks of $S$. terebinthifolius indicated the presence of anthraquinones, xanthones and steroids [9]. Additionally, essential oils from leaves, flowers and fruits of S. terebinthifolius were also analyzed, and proved to be composed of mono- and sesquiterpenes. With regards to the evaluation of the biological activity, the volatile oils of fruits showed allelopathic, cytotoxic and trypanocidal activities, while the leaf oil showed cytotoxic activity [10-15]. Furthermore, previous work demonstrated anti-Leishmania amazonensis (promastigotes) activity of the aqueous and hydro-alcoholic extracts from leaves of S. terebinthifolius [16]. Considering other plants from the genus Schinus, the MeOH extract of the leaves and fruits of $S$. molle have also shown activity against L. infantum, Trypanosoma brucei, T. cruzi, and Plasmodium falciparum [17].

Leishmaniasis and Chagas' disease are parasitic diseases caused by the protozoans Leishmania spp. and Trypanosoma cruzi, respectively. They are recognized by World Health Organization among the World's most neglected diseases, affecting millions of people [18]. Considering the limited and highly toxic therapeutic arsenal, the study of alternative therapies is essential. In continuation of the investigation of bioactive compounds from Brazilian flora [19-22], the present study was undertaken to determine the effectiveness and cytotoxicity of three main compounds isolated from leaves extract of $S$. terebinthifolius ( $E$ - and $Z$-masticadienoic acids and $Z$-schinol) against promastigotes and intracellular amastigotes of Leishmania (L.) infantum, as well as trypomastigote forms of Trypanosoma cruzi. Aiming to establish relationships between the chemical structures and the antiparasitic activity, nine semi-synthetic tirucallane derivatives were obtained and tested against parasites and mammalian cells.

\section{Results and Discussion}

Schinus terebinthifolius is a Brazilian plant that produces great amounts of tirucallane derivatives such as (Z)-masticadienoic (1) and (E)-masticadienoic (2) acids as well as (Z)-schinol (3). In this work, 
these compounds were isolated from leaves of this plant using several chromatographic techniques and their structures were confirmed by NMR and ESI-MS spectral analysis and comparison with data described in the literature [5,23]. The triterpenoids $\mathbf{1}-\mathbf{3}$ were subjected to different reactions: reduction of carbonyl group at C-3, methylation of carboxyl group at C-27, acetylation of hydroxyl group at C-3 and hydrogenation of double bond at C-24, to afford nine derivatives (1a-c, 2a-d, 3a, and 3b-Figure 1), being $\mathbf{1 c}, \mathbf{2 c}, \mathbf{2 d}, \mathbf{3 a}$, and $\mathbf{3 b}$ new compounds. The structures of these compounds were confirmed by MS and ${ }^{13} \mathrm{C}-\mathrm{NMR}$ by the comparison of respective spectral data with those recorded for $\mathbf{1}-\mathbf{3}$. In the case of carbonyl reduction (compounds $\mathbf{1 a}$ and 2a) the absence of a peak at $\delta 217$ associated to the occurrence of a signal at range $\delta 79-76$ indicates the presence of an oxymethine carbon at C-3. The ${ }^{13} \mathrm{C}-\mathrm{NMR}$ spectra of derivatives $\mathbf{2 b}, \mathbf{2 c}$ and $\mathbf{3 b}$ showed additional peaks assigned to carbonyl ( $\delta$ 170) and methyl $(\delta 20)$ carbons of acetyl group at C-3. The hydrogenated derivatives $\mathbf{1 b}, \mathbf{1} \mathbf{c}$ and $\mathbf{2 c}$ showed two additional units in the ESI-MS mass spectra in comparison with $\mathbf{1}$ and $\mathbf{2 b}$. This data, associated to the absence of peaks assigned to C-24 and C-25 at $\delta 146$ and 126, respectively, indicated that the hydrogenation occurs exclusively at $\Delta^{24}$. Finally, structures of methyl esters $\mathbf{2 d}$ and 3a were confirmed by the presence of additional peaks at $\delta 52$ in the respective ${ }^{13} \mathrm{C}$-NMR spectra.

Figure 1. Structures of natural compounds 1-3 and semi-synthetic 1a-c, 2a-d, 3a, and $\mathbf{3 b}$ tirucallane triterpenoids.

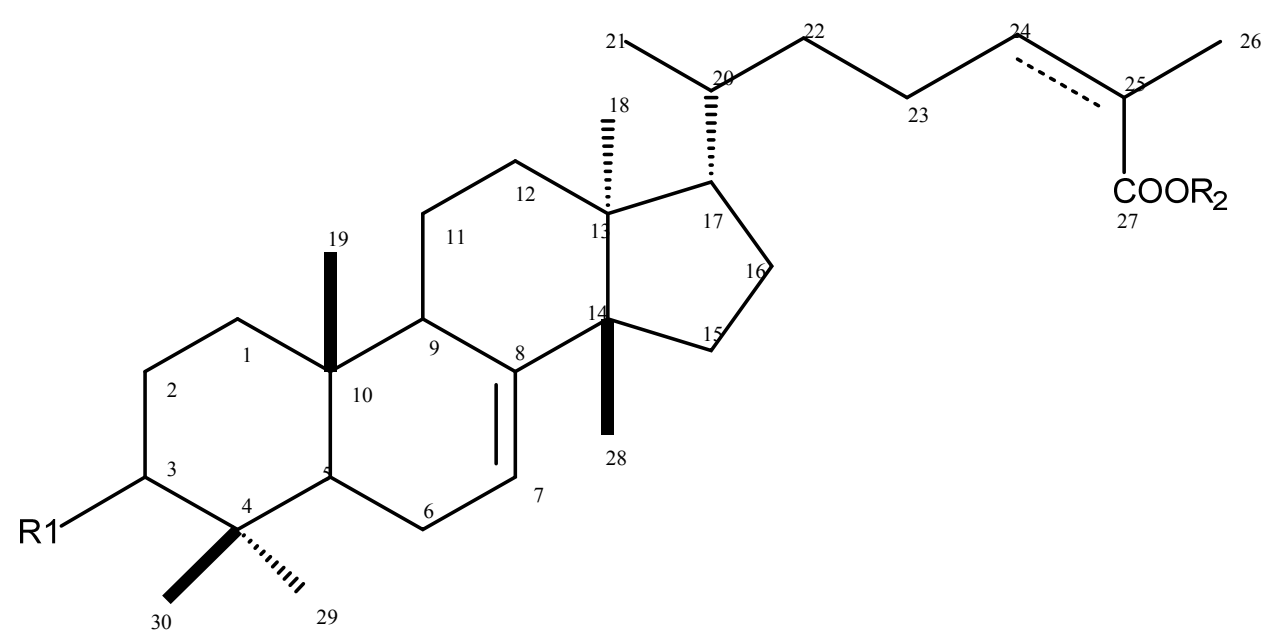

$1 \mathrm{R}_{1}=\mathrm{O} ; \mathrm{R}_{2}=\mathrm{H} ; \Delta^{24 Z}$

1a $\mathrm{R}_{1}=\min \mathrm{OH} ; \mathrm{R}_{2}=\mathrm{H} ; \Delta^{24 Z}$

$1 \mathbf{b} \mathrm{R}_{1}=$-mиn $\mathrm{OH} ; \mathrm{R}_{2}=\mathrm{H}$

1 c $\mathrm{R}_{1}=\mathrm{O} ; \mathrm{R}_{2}=\mathrm{H}$

$2 \mathrm{R}_{1}=\mathrm{O} ; \mathrm{R}_{2}=\mathrm{H} ; \Delta^{24 E}$

2a $\mathrm{R}_{1}=\operatorname{mr} \mathrm{OH} ; \mathrm{R}_{2}=\mathrm{H} ; \Delta^{24 E}$

2b R $\mathrm{R}_{1}=\operatorname{mr} \mathrm{OAc} ; \mathrm{R}_{2}=\mathrm{H} ; \Delta^{24 E}$

2c $\mathrm{R}_{1}=-$ ma $^{2} \mathrm{OAc} ; \mathrm{R}_{2}=\mathrm{H}$

2d R $1=\mathrm{O} ; \mathrm{R}_{2}=\mathrm{Me} ; \Delta^{24 E}$

$3 \mathrm{R}_{1}=\ldots \cdot \cdots \cdot \mathrm{OH} ; \mathrm{R}_{2}=\mathrm{H} ; \Delta^{24 Z}$

3a $\mathrm{R}_{1}=\cdots \cdots+\cdots \mathrm{OH} ; \mathrm{R}_{2}=\mathrm{Me} ; \Delta^{24 Z}$

3b $\mathrm{R}_{1}=\cdots \cdot+\cdots$ OAc; $\mathrm{R}_{2}=\mathrm{Me} ; \Delta^{24 Z}$ 
The antileishmanial and antitrypanosomal activities of three natural and nine semi-synthetic derivatives of tirucallane triterpenoids were evaluated against $L$. (L.) infantum and T. cruzi. According to the colorimetric assay of MTT and light microscopy, seven compounds killed 100\% of trypomastigote forms of $T$. cruzi at the highest tested concentration, resulting in $\mathrm{IC}_{50}$ values in the range of 15.75 to $58.36 \mu \mathrm{g} / \mathrm{mL}$ (Table 1 ).

Table 1. Antiparasitic (antileishmanial and antitrypanosomal) and cytotoxic effects of natural compounds $\mathbf{1}-\mathbf{3}$, semi-synthetic $\mathbf{1 a - c , ~ 2 a - d , ~ 3 a , ~ a n d ~} \mathbf{3 b}$ and standards.

\begin{tabular}{|c|c|c|c|c|c|c|}
\hline \multirow[b]{2}{*}{ Compounds } & \multicolumn{3}{|c|}{$\mathrm{IC}_{50}(\mathrm{~g} / \mathrm{mL})^{\mathrm{a}} \mathrm{CI} 95 \%$} & \multirow{2}{*}{$\frac{\mathrm{CC}_{50}(\mu \mathrm{g} / \mathrm{mL})^{\mathrm{b}} \mathrm{CI} 95 \%}{\mathrm{NCTC}}$} & \multicolumn{2}{|c|}{ SI } \\
\hline & $\begin{array}{c}\text { L. infantum } \\
\text { Promastigotes }\end{array}$ & $\begin{array}{l}\text { L. infantum } \\
\text { Amastigotes }\end{array}$ & $\begin{array}{c}\text { T. cruzi } \\
\text { Trypomastigotes }\end{array}$ & & $\mathbf{A M A}^{\mathbf{c}}$ & TRY $^{d}$ \\
\hline 1 & NA & $66.51(47.68-92.79)$ & NA & $>200$ & $>3$ & - \\
\hline $1 \mathrm{a}$ & NA & NA & $20.18(16.70-24.39)$ & $69.50(64.01-75.45)$ & - & 3.4 \\
\hline $1 \mathrm{~b}$ & NA & NA & $17.64(15.97-19.50)$ & $76.39(70.02-83.33)$ & - & 4.3 \\
\hline $1 \mathrm{c}$ & NA & NA & NA & $>200$ & - & - \\
\hline 2 & NA & $64.90(41.48-101.50)$ & $15.75(9.80-25.30)$ & $96.48(77.38-120.30)$ & 1.5 & 6.1 \\
\hline $2 a$ & NA & $97.59(89.82-106.00)$ & $29.59(25.61-34.18)$ & $95.49(65.22-139.80)$ & 1.0 & 3.2 \\
\hline $2 \mathbf{b}$ & NA & NA & $58.36(42.82-79.55)$ & $69.31(38.74-82.64)$ & - & 1.1 \\
\hline $2 c$ & NA & NA & $49.20(41.69-58.05)$ & $57.78(56.10-59.52)$ & - & 1.2 \\
\hline 2d & NA & NA & NA & $>200$ & - & - \\
\hline 3 & $57.82(54.01-61.91)$ & $28.95(19.87-42.16)$ & $16.28(8.94-29.60)$ & $69.50(64.01-75.45)$ & 2.4 & 4.3 \\
\hline $3 a$ & NA & NA & NA & $>200$ & - & - \\
\hline $\mathbf{3 b}$ & NA & NA & NA & $>200$ & - & - \\
\hline miltefosine & 6.87 & 7.25 & - & 49.72 & - & - \\
\hline benznidazole & - & - & 114.68 & - & - & - \\
\hline
\end{tabular}

$\mathrm{IC}_{50}: 50 \%$ inhibitory concentration; $\mathrm{CC}_{50}: 50 \%$ cytotoxic concentration (mammalian cells); NA: not active; CI95\%: 95\% Confidence Interval; SI AMA: selectivity index amastigotes $\left(\mathrm{CC}_{50}\right.$ mammalian cells/IC $\mathrm{I}_{50}$ Leishmania amastigotes); SI TRY: selectivity index trypomastigotes $\left(\mathrm{CC}_{50}\right.$ mammalian cells/IC 50 trypomastigotes).

Despite the lack of activity of compound $\mathbf{1}$, the semi-synthetic derivatives $\mathbf{1 a}$ and $\mathbf{1 b}$ demonstrated antitrypanosomal activity, with $\mathrm{IC}_{50}$ values of 20.18 and $17.64 \mu \mathrm{g} / \mathrm{mL}$, respectively. In addition, an enhanced mammalian toxicity was also observed. Otherwise, compound $\mathbf{2}$, the most effective against the trypomastigotes $\left(\mathrm{IC}_{50} 15.75 \mu \mathrm{g} / \mathrm{mL}\right.$ ), demonstrated a higher activity when compared to the semi-synthetic derivatives $\mathbf{2 a}, \mathbf{2 b}$ and $\mathbf{2 c}$, which showed moderate inhibitory effects and $\mathrm{IC}_{50}$ values between 29.59 and $58.36 \mu \mathrm{g} / \mathrm{mL}$. Considering the $95 \%$ confidence intervals, the mammalian toxicity of $\mathbf{2 a}, \mathbf{2 b}$ and $\mathbf{2 c}$ was comparable to that of the natural prototype 2. Likewise, the natural compound $\mathbf{3}$, which showed an $\mathrm{IC}_{50}$ value of $16.28 \mu \mathrm{g} / \mathrm{mL}$ against trypomastigotes, also rendered less effective derivatives after methylation at C-27 (3a) and acetylation at C-3 (3b), although the derivatization resulted in no more cytotoxic compounds when compared to the natural compound 3. Benznidazole was used as a standard drug and gave an $\mathrm{IC}_{50}$ value of $114.68 \mu \mathrm{g} / \mathrm{mL}$ [21]. Considering the relation between the antiparasitic activity and mammalian cytotoxicity, given by the selectivity index $\left(\mathrm{CC}_{50} / \mathrm{IC}_{50}\right)$, compounds $\mathbf{2}, \mathbf{3}$ and the semi-synthetic derivative $\mathbf{1 b}$ demonstrated the highest indexes, ranging from 4 to 6 . According to the Food and Drug Administration guidance for the development of 
drugs [24], it is desirable to have a high selectivity index giving maximum activity with minimal cell toxicity.

Among the twelve tested compounds, only the natural prototype $\mathbf{3}$ showed effectiveness against L. infantum promastigotes, with an $\mathrm{IC}_{50}$ value of $57.82 \mu \mathrm{g} / \mathrm{mL}$. The modifications of the semi-synthetic tirucallane triterpenoid derivatives (compounds 1a-1c, $\mathbf{2 a - 2 d}, \mathbf{3 a}$ and $\mathbf{3 b}$ ) showed no improvement of the antileishmanial effectiveness against the extracellular forms of L. infantum. However, when tested against the intracellular amastigotes, four compounds $(\mathbf{1}, \mathbf{2}, \mathbf{2 a}$ and $\mathbf{3})$ resulted in $\mathrm{IC}_{50}$ values in the range of 28.95 to $97.59 \mu \mathrm{g} / \mathrm{mL}$. This effect could be ascribed to a possible macrophage activation, which could also have contributed to an oxygen burst and up-regulation of cytokines by host cells [25]. The possible immunomodulatory effect of these compounds may be investigated in future assays. Similarly, the pentavalent antimonial glucantime, the main clinical drug in use for leishmaniasis has also shown no effectiveness against the extracellular forms of the parasite, and its antiparasitic activity has been attributed to host cell activation [26]. Except for compound 1, which showed no mammalian toxicity up to the highest tested concentration $(>200 \mu \mathrm{g} / \mathrm{mL})$, compounds 2 and $\mathbf{3}$ resulted in $\mathrm{CC}_{50}$ values of 96 and $69 \mu \mathrm{g} / \mathrm{mL}$, respectively. Considering the selectivity index, compound 1 was the most promising candidate without toxicity to NCTC cells, showing a value higher than $\mathbf{3}$. Miltefosine showed a $50 \%$ cytotoxic concentration $\left(\mathrm{CC}_{50}\right)$ of $49.72 \mu \mathrm{g} / \mathrm{mL}$ and resulted in a SI of 7 . Miltefosine was used as a standard drug against promastigotes and amastigotes, with $\mathrm{IC}_{50}$ values of 6.87 and $7.25 \mu \mathrm{g} / \mathrm{mL}$, respectively [27].

The decision tree (DT) model (Figure 2) selected with the aim of establishing relationships between chemical structures and antitrypanosomal activity of compounds $\mathbf{1 a}-\mathbf{c}, \mathbf{2 a}-\mathbf{d}, \mathbf{3 a}$ and $\mathbf{3 b}$ used the DD5 descriptor. This molecular descriptor quantifies the variation between the maximum hydrophobic volume obtained upon variation of ligand conformation and the hydrophobic volume of the imported three dimensional structure into Volsurf at a Molecular Interaction Fields (MIF) energy value of $-1.0 \mathrm{kcal} / \mathrm{mol}[28]$.

Triterpenoids 1, 1c and 2d displayed equal or lower DD5 values than 0.125 . Thus, it is possible to infer that compounds with a carbonyl group at C-3 with $Z$ configuration at $\Delta^{24}$, with an ester group at C-27, or without a double bond between C-24/C-25 showed lower differences of hydrophobic volumes and are inactive against the $T$. cruzi. The DT model predicts for all 12 compounds (100\%) of antitrypanosomal activity for the training set and 11 compounds (92.9\%) for internal validation (Table 2). The obtained data also suggested that the stereochemistry of hydroxyl group at C-3 to triterpenoids $\mathbf{3}$ and $\mathbf{1 a}$ was determinant to antileishmanial activity (promastigote and amastigote forms of L. infantum) since these compounds displayed the same planar structure but different configuration. However, using a DT model with only one descriptor as DD8 (differences of the hydrophobic volumes at energy level $-1.6 \mathrm{kcal} / \mathrm{mol}$ ) it was possible to predict activity against $L$. infantum amastigotes for 10 compounds $(83.3 \%)$ of the training set and internal validation (Table 2) [29]. The data showed that compounds with higher values of DD8 than 0.125 were active. Triterpenoids with carbonyl or hydroxyl at C-3, double bond at C-24, and carboxylic acid at C-27, showed higher values of DD8 (compounds $\mathbf{1}$, 1a, 2 and 3). It is important to highlight that the prediction activity error of compound 1a was due to DD8, which is a three dimensional descriptor that does not encode directly the stereochemistry but the difference of $3 \mathrm{D}$ conformations of the compounds. 
Figure 2. Decision Trees (DT) generated for the set of triterpenoids with antiparasitic activity. (A) The compounds with higher values of DD5 (differences of the hydrophobic volumes at energy level of $-1.0 \mathrm{kcal} / \mathrm{mol}$ ) than 0.125 were active against $T$. cruzi trypomastigotes. (B) Compounds with higher values of DD8 (differences of the hydrophobic volumes at energy level of $-1.6 \mathrm{kcal} / \mathrm{mol}$ ) than 0.125 were active against L. infantum amastigotes. (C) Triterpenoids with DD4 (differences of the hydrophobic volumes at energy level of $-0.8 \mathrm{kcal} / \mathrm{mol}$ ) values higher than 0.8125 or DD5 values lower or equal to 0.25 were not cytotoxic against NCTC. The numbers in brackets show the number of compounds correctly classified/incorrectly as active (A) or inactive (I).

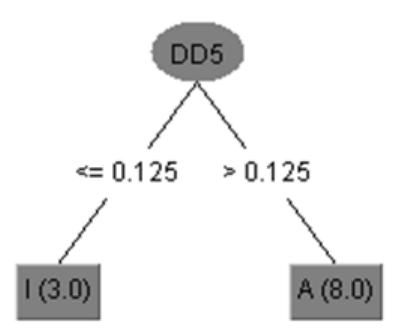

A

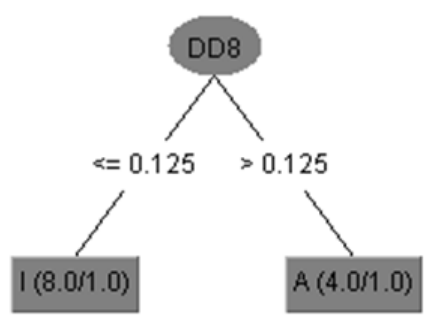

B

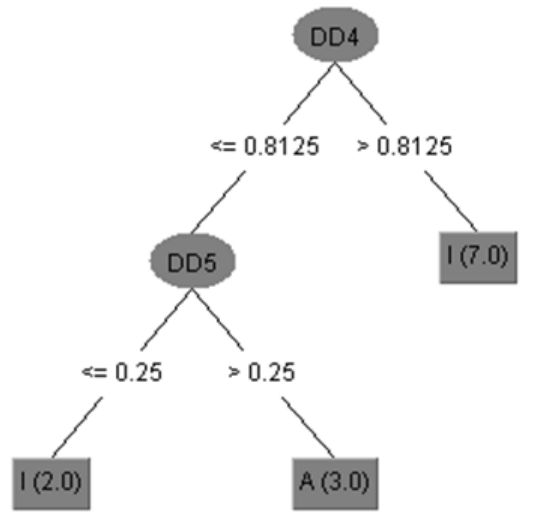

C

Table 2. Comparison of experimental antileishmanial, antitrypanosomal and cytotoxic activities with data predicted by Decision tree models for the training set and internal cross validation (leave-one-out).

\begin{tabular}{cccccccccc}
\hline & \multicolumn{1}{c}{ T. cruzi (Trypomastigotes) } & \multicolumn{2}{c}{ L. infantum (Amastigotes) } & \multicolumn{3}{c}{ NCTC } \\
\hline Compounds & Experimental & Train & Validation & Experimental & Train & Validation & Experimental & Train & Validation \\
\hline $\mathbf{1}$ & I & I & I & A & A & A & I & I & I \\
$\mathbf{2}$ & A & A & A & A & A & A & I & I & I \\
$\mathbf{2 a}$ & A & A & A & A & I & I & I & I & I \\
$\mathbf{1 a}$ & A & A & A & I & A & A & A & A & A \\
$\mathbf{1 b}$ & A & A & A & I & I & I & A & A & I \\
$\mathbf{2 b}$ & A & A & A & I & I & I & I & I & I \\
$\mathbf{2 d}$ & I & I & A & I & I & I & I & I & A \\
$\mathbf{3}$ & A & A & A & A & A & A & A & A & A \\
$\mathbf{1 c}$ & I & I & I & I & I & I & I & I & A \\
$\mathbf{2 c}$ & A & A & A & I & I & I & I & I & I \\
3a & A & A & A & I & I & I & I & I & I \\
3b & A & A & A & I & I & I & I & I & I \\
\hline
\end{tabular}

Cytotoxicity of triterpenoids was also related to the difference of hydrophobic values (Figure 2) once descriptors DD4 and DD5 were selected and compounds with higher values than 0.8125 to DD4 (differences of the hydrophobic volumes at energy level of $-0.8 \mathrm{kcal} / \mathrm{mol}$ ) or lower or equal values than 0.25 to DD5 were not cytotoxic against NCTC. DT model predicted $100 \%$ of cytotoxicity of the training set and $75 \%$ of internal validation (Table 2 ). Therefore, the cytotoxic compounds displayed 
hydroxyl group at C-3 and $Z$ configuration or absence of double bond between C-24 and C-25 with carboxylic acid at C-27 (compounds $\mathbf{1 a}, \mathbf{1 b}$ and $\mathbf{3}$ ).

\section{Experimental}

\subsection{General Experimental Procedures}

All solvents used were of analytical grade and purchased from CAAL (São Paulo, Brazil). Silica gel (230-400 mesh, Merck, Darmstadt, Germany) and Sephadex LH-20 (Aldrich, St. Louis, MO, USA) were used for column chromatographic separation, while silica gel $60 \mathrm{~F}_{254}$ (Merck) was used for analytical TLC $(0.25 \mathrm{~mm}) .{ }^{1} \mathrm{H}$ and ${ }^{13} \mathrm{C}$ spectra were recorded, respectively, at 300 and $75 \mathrm{MHz}$ in a Bruker Ultrashield 300 Advance III spectrometer. $\mathrm{CDCl}_{3}$ (Aldrich) was used as solvent and the residual peak of the non-deuterated solvent as internal standard. Chemical shifts $(\delta)$ are reported in ppm and coupling constant $(J)$ in Hz. ESI-MS were measured with a Platform II mass spectrometer (Micromass, MA, USA), operating in negative mode.

\subsection{Plant Material}

Leaves of $S$. terebinthifolius were randomly collected from an individual tree at Mogi-Guaçu region (São Paulo State, Brazil) on February/2010 by Dr. Maria Claudia Marx Young from Instituto de Botânica (São Paulo, Brazil), where a reference specimen (SP272591) was deposited.

\subsection{Extraction and Isolation of Natural Triterpenoids 1-3}

The leaves of $S$. terebinthifolius were dried at $40{ }^{\circ} \mathrm{C}$ during 7 days. After grinding, the plant material $(1 \mathrm{~kg})$ was extracted with $n$-hexane $(10 \times 1 \mathrm{~L})$ for removal of fatty material. The remaining material was submitted to an exhaustive extraction with $\mathrm{EtOH}$ at room temperature using an accelerated solvent extractor system (Dionex ASE-350). Distillation of the solvent under reduced pressure yielded the crude EtOH extract, which was partitioned between EtOH- $\mathrm{H}_{2} \mathrm{O}$ 1:2 $(500 \mathrm{~mL})$ and hexane $(4 \times 250 \mathrm{~mL})$ to afford $22 \mathrm{~g}$ of $n$-hexane phase after solvent removal under reduced pressure. Thus, part of the $n$-hexane phase (20 g) was subjected to fractionation by silica gel column chromatography and eluted with increasing amount of EtOAc in $n$-hexane to afford 37 fractions $(125 \mathrm{~mL}$ each). After analysis by TLC, these fractions were pooled into eight groups (A-H). Group E $(1,001 \mathrm{mg})$ was subjected to fractionation on a Sephadex LH-20 column $(3 \times 50 \mathrm{~cm}$-flow $1.0 \mathrm{~mL} / \mathrm{min})$ and eluted with $\mathrm{MeOH}$, yielding 30 fractions $(3 \mathrm{~mL}$ each), which were pooled into six groups after analysis by TLC (E1 to E6). Groups E2 (310 mg) and E3 (500 mg) consisted of $\mathbf{2}$ and 1, respectively. Group F (1800 mg) was subjected to separation on a Sephadex LH-20 column $(3 \times 60 \mathrm{~cm}-$ flow $0.7 \mathrm{~mL} / \mathrm{min})$ and eluted with $\mathrm{MeOH}$, yielding 40 fractions $(3 \mathrm{~mL}$ each), which, after monitoring by TLC, were pooled into four groups (C1 to C4). Group C2 (1020 mg) was subjected to fractionation on a Sephadex LH-20 column $(3 \times 50 \mathrm{~cm}-$ flow $1.0 \mathrm{~mL} / \mathrm{min})$ eluted with $\mathrm{MeOH}$, yielding 27 fractions ( $3 \mathrm{~mL}$ each), which were pooled into four groups (C2/1 to C-2/4) after analysis by TLC. Purification of group C2/3 (580 mg) by silica gel column chromatography $(3 \times 40 \mathrm{~cm})$, using increasing amounts of EtOAc in hexane, allowed the isolation of $\mathbf{3}(90 \mathrm{mg})$. 
3-Oxotirucalla-7,24Z-dien-27-oic acid (Z-masticadienoic acid, 1). Amorphous solid. ESI-MS m/z 453 $[\mathrm{M}-\mathrm{H}]^{-} ;{ }^{1} \mathrm{H}-\mathrm{NMR}\left(\mathrm{CDCl}_{3}\right), \delta / \mathrm{ppm}: 6.02(\mathrm{t}, J=6.0 \mathrm{~Hz}, \mathrm{H}-24), 5.30(\mathrm{t}, J=3.0 \mathrm{~Hz}, \mathrm{H}-7), 2.77$ (td, $J=15.1$ and $6.0 \mathrm{~Hz}, \mathrm{H}-3), 2.56$ (m, H-23), 2.27 (m, H-5), 2.23 (m, H-2), 2.09 (m, H-6), 1.97 (m, H-16), 1.90 (s, $\left.\mathrm{CH}_{3}-26\right), 1.89$ (m, H-9), 1.57 (m, H-22), 1.54 (m, H-20), 1.52 (m, H-15), 1.50 (m, $\mathrm{H}-12), 1.47$ (m, H-17), 1.41 (m, H-1), 1.12 (s, $\left.\mathrm{CH}_{3}-28\right), 1.05$ (s, $\left.\mathrm{CH}_{3}-30\right), 1.00$ (s, $\left.\mathrm{CH}_{3}-29\right), 0.89$ (m, $\mathrm{H}-11), 0.88$ (d, $\left.J=6.0 \mathrm{~Hz}, \mathrm{CH}_{3}-21\right), 0.87$ (s, $\left.\mathrm{CH}_{3}-18\right), 0.77$ (s, $\left.\mathrm{CH}_{3}-19\right) .{ }^{13} \mathrm{C}-\mathrm{NMR}\left(\mathrm{CDCl}_{3}\right), \delta / \mathrm{ppm}$ : 217.1 (C-3), 173.4 (C-27), 146.2 (C-24), 146.1 (C-8), 126.5 (C-25), 117.8 (C-7), 52.9 (C-17), 51.2 (C-14), 48.6 (C-5), 48.4 (C-9), 47.9 (C-4), 43.5 (C-13), 38.5 (C-1), 36.1 (C-20), 35.7 (C-10 and C-15), 35.0 (C-2), 34.1 (C-12), 33.8 (C-22), 28.2 (C-16), 27.4 (C-28), 27.3 (C-29), 26.9 (C-23), 25.4 (C-30), 24.5 (C-6), 20.6 (C-26), 18.3 (C-18), 18.2 (C-11), 18.0 (C-21), 13.0 (C-19).

3-Oxotirucalla-7,24E-dien-27-oic acid (E-masticadienoic acid, 2). Amorphous solid. ESI-MS m/z 453 $[\mathrm{M}-\mathrm{H}]^{-} ;{ }^{1} \mathrm{H}-\mathrm{NMR}\left(\mathrm{CDCl}_{3}\right), \delta / \mathrm{ppm}: 6.06(\mathrm{t}, J=6.9 \mathrm{~Hz}, \mathrm{H}-24), 5.30(\mathrm{~m}, \mathrm{H}-7), 2.77(\mathrm{td}, J=15.0$ and $6.0 \mathrm{~Hz}, \mathrm{H}-2), 2.56$ (m, H-23), 2.24 (m, H-2), 2.10 (m, H-6), 2.09 (m, H-5), 2.03 (m, H-16), 2.00 (m, H-9), 1.92 (s, $\left.\mathrm{CH}_{3}-26\right), 1.73$ (m, H-15), 1.60 (m, H-12), 1.57 (m, H-11), 1.49 (m, H-1), 1.47 (m, H-20), 1.42 (m, H-17), 1.30 (m, H-22), 1.12 (s, $\left.\mathrm{CH}_{3}-19\right), 1.04$ (s, $\left.\mathrm{CH}_{3}-29\right), 1.00$ (s, $\mathrm{CH}_{3}-28$ and $\left.\mathrm{CH}_{3}-30\right), 0.89$ (d, $\left.J=6.0 \mathrm{~Hz}, \mathrm{CH}_{3}-21\right), 0.81\left(\mathrm{~s}, \mathrm{CH}_{3}-18\right) .{ }^{13} \mathrm{C}-\mathrm{NMR}\left(\mathrm{CDCl}_{3}\right), \delta / \mathrm{ppm}: 217.1(\mathrm{C}-3), 173.1(\mathrm{C}-27), 145.6$ (C-24), 145.8 (C-8), 126.7 (C-25), 117.9 (C-7), 52.2 (C-17), 51.1 (C-14), 52.8 (C-5), 47.8 (C-4), 43.5 (C-13), 48.5 (C-9), 38.5 (C-1), 36.0 (C-20), 35.0 (C-23), 34.9 (C-10), 34.6 (C-2), 34.0 (C-15), 33.6 (C-12), 26.0 (C-22), 28.2 (C-16), 27.4 (C-30), 24.5 (C-28), 24.3 (C-6), 21.9 (C-18), 21.6 (C-29), 18.2 (C-11), 18.1 (C-21), 12.7 (C-19), 11.9 (C-26).

3 $\alpha$-Hydroxytirucalla-7,24Z-dien-27-oic acid (Z-schinol, 3). Amorphous solid. ESI-MS m/z 455 $[\mathrm{M}-\mathrm{H}]^{-} ;{ }^{1} \mathrm{H}-\mathrm{NMR}\left(\mathrm{CDCl}_{3}\right), \delta / \mathrm{ppm}: 6.07(\mathrm{t}, J=6.3 \mathrm{~Hz}, \mathrm{H}-24), 5.28(\mathrm{~m}, \mathrm{H}-7), 3.46$ (dd, $J=10.2$ and $5.4 \mathrm{~Hz}, \mathrm{H}-3), 2.50$ (m, H-9), 2.46 (m, H-23), 2.05 (s, $\left.\mathrm{CH}_{3}-26\right), 2.04$ (m, H-2), 1.97 (m, H-16), 1.95 (s, $\left.\mathrm{CH}_{3}-30\right), 1.91$ (m, H-5), 1.90 (m, H-6), 1.59 (m, H-12), 1.56 (m, H-11), 1.46 (m, H-1), 1.43 (m, H-15), 1.42 (m, H-17), 1.39 (m, H-20), 1.37 (m, H-22), 0.93 (s, $\left.\mathrm{CH}_{3}-28\right), 0.90$ (s, $\left.\mathrm{CH}_{3}-29\right), 0.89$ (d, $\left.J=6.0 \mathrm{~Hz}, \mathrm{CH}_{3}-21\right), 0.83\left(\mathrm{~s}, \mathrm{CH}_{3}-18\right), 0.77\left(\mathrm{~s}, \mathrm{CH}_{3}-19\right) .{ }^{13} \mathrm{C}-\mathrm{NMR}\left(\mathrm{CDCl}_{3}\right), \delta / \mathrm{ppm}: 173.6(\mathrm{C}-27)$, 146.1 (C-24), 146.0 (C-8), 125.7 (C-25), 117.8 (C-7), 76.4 (C-3), 53.3 (C-17), 51.6 (C-14), 48.6 (C-9), 44.5 (C-5), 43.9 (C-13), 37.4 (C-4), 36.4 (C-2), 36.2 (C-1 and C-20), 36.1 (C-22), 35.6 (C-10), 34.7 (C-12), 34.0 (C-15), 28.2 (C-16 and C-28), 27.4 (C-30), 26.9 (C-23), 24.3 (C-6), 22.5 (C-29), 21.4 (C-18), 20.6 (C-26), 18.7 (C-21), 18.5 (C-11), 13.0 (C-19).

\subsection{Preparation of Semi-Synthetic Compounds}

\subsubsection{Reduction of the Carbonyl Group at C-3 (Compounds $\mathbf{1}$ and 2)}

To a solution of $\mathbf{1}(100 \mathrm{mg})$ or $\mathbf{2}(50 \mathrm{mg})$ dissolved in $\mathrm{MeOH}(10 \mathrm{~mL})$ was added $\mathrm{NaBH}_{4}(42 \mathrm{mg})$ in small portions and carefully. The reaction mixture was stirred overnight at room temperature. After addition of $\mathrm{H}_{2} \mathrm{O}$, the solvent was partially evaporated under reduced pressure. The residue was extracted with EtOAc $(3 \times 25 \mathrm{~mL})$ and the combined organic layers were dried over $\mathrm{Na}_{2} \mathrm{SO}_{4}$, filtered and concentrated. Purification by silica gel chromatography (hexane/EtOAc 7:3) afforded 1a (41 mg) or $2 \mathbf{a}(46 \mathrm{mg})$. 


\subsubsection{Hydrogenation of $\Delta^{24}$ (Compounds $\left.\mathbf{1}, \mathbf{1 a}, \mathbf{2 b}\right)$}

In a high-pressure reactor (stainless steel), was added $\mathbf{1}(20 \mathrm{mg})$ or $\mathbf{1 a}(20 \mathrm{mg})$ or $\mathbf{2 b}(15 \mathrm{mg})$ and Ni-Raney catalyst $(50 \mathrm{mg})$. After addition of $\mathrm{H}_{2}(20 \mathrm{~atm})$, the mixture was stirred for $3 \mathrm{~h}$ at $100{ }^{\circ} \mathrm{C}$. Then, the product was dissolved in $\mathrm{CH}_{2} \mathrm{Cl}_{2}$ and the catalyst removed by filtration over a bed of Celite. Purification by silica gel chromatography (hexane/EtOAc 9:1) afforded 1c (15 mg) or 1b (14 $\mathrm{mg})$ or $\mathbf{2 c}(9 \mathrm{mg})$.

\subsubsection{Acetylation of Hydroxyl Group at C-3 (Compounds 2a and 3a)}

A solution of $\mathbf{2 a}(50 \mathrm{mg})$ or $\mathbf{3 a}(15 \mathrm{mg})$ was dissolved in pyridine $(4 \mathrm{~mL})$ and cooled to $0{ }^{\circ} \mathrm{C}$. Acetic anhydride $(2 \mathrm{~mL})$ was added and was stirred overnight at room temperature. Excess of reagents were removed under reduced pressure. After addition of $\mathrm{H}_{2} \mathrm{O}(5 \mathrm{~mL})$, the residue was extracted with $\mathrm{CH}_{2} \mathrm{Cl}_{2}(3 \times 25 \mathrm{~mL})$. The organic layer was dried over $\mathrm{Na}_{2} \mathrm{SO}_{4}$, filtered and concentrated. Purification by silica gel chromatography with hexane/EtOAc (7:3) afforded $\mathbf{2 b}$ (35 mg) or hexane/EtOAc (95:5) afforded $\mathbf{3 b}$ (10 mg).

\subsubsection{Methylation of Carboxylic Acid (Compounds 2 and 3)}

To a solution of $\mathrm{KOH}(1.7 \mathrm{~g})$ in $\mathrm{H}_{2} \mathrm{O}(2.3 \mathrm{~mL})$ and $\mathrm{EtOH}(8.3 \mathrm{~mL})$ was added a solution of Diazald $(7.2 \mathrm{~g})$ dissolved in $\mathrm{Et}_{2} \mathrm{O}(80 \mathrm{~mL})$. This mixture was heated and the product distillated to afford ether solution of diazomethane $(0.75 \mathrm{~g})$. Immediately, an excess of diazomethane was added to 2 (70 mg) or $3(25 \mathrm{mg})$. The organic layer was dried over $\mathrm{Na}_{2} \mathrm{SO}_{4}$, filtered and concentrated under reduced pressure. Purification by silica gel chromatography (hexane/EtOAc 9:1) afforded compounds $\mathbf{2 d}(50 \mathrm{mg})$ or $\mathbf{3 a}(21 \mathrm{mg})$.

$3 \xi$-Hydroxytirucalla-7,24Z-dien-27-oic acid (1a). Amorphous solid. ESI-MS m/z 455 [M-H] ;

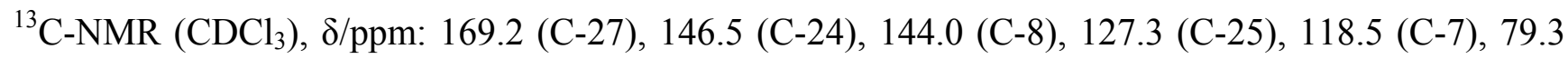
(C-3), 53.3 (C-17), 51.6 (C-14), 49.1 (C-9), 44.8 (C-5), 43.9 (C-13), 37.7 (C-4), 36.5 (C-20), 36.1 (C-22), 35.1 (C-10), 34.4 (C-15), 34.3 (C-12), 31.7 (C-1), 28.6 (C-16), 28.2 (C-28), 27.5 (C-30), 26.9 (C-2), 26.1 (C-23), 24.3 (C-6), 22.0 (C-29 and C-18), 20.9 (C-26), 18.4 (C-21 and C-11), 13.2 (C-19).

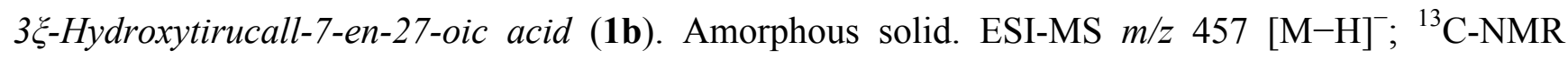

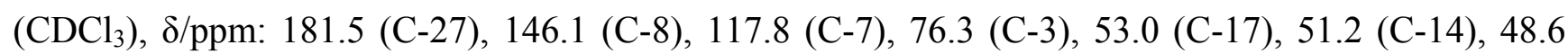
(C-9), 44.5 (C-5), 43.4 (C-13), 39.2 (C-25), 37.4 (C-4), 36.0 (C-20), 35.8 (C-24), 35.0 (C-10), 34.9 (C-22), 34.7 (C-12), 34.0 (C-15), 31.2 (C-1), 28.2 (C-16), 27.7 (C-23 and C-28), 25.3 (C-2), 24.0 (C-6), 21.9 (C-18), 21.8 (C-29), 21.6 (C-30), 18.3 (C-11), 17.9 (C-21), 17.0 (C-26), 12.9 (C-19).

3-Oxotirucall-7-en-27-oic acid (1c). Amorphous solid. ESI-MS $m / z 455[\mathrm{M}-\mathrm{H}]^{-} ;{ }^{13} \mathrm{C}-\mathrm{NMR}\left(\mathrm{CDCl}_{3}\right)$, ठ/ppm: 217.0 (C-3), 182.4 (C-27), 146.0 (C-8), 117.8 (C-7), 53.0 (C-5), 52.3 (C-17), 51.2 (C-14), 48.5 (C-9), 47.9 (C-4), 43.5 (C-13), 38.5 (C-1), 35.8 (C-20 and C-24), 35.7 (C-25), 35.0 (C-10 and C-22), 34.9 (C-2), 34.0 (C-15), 33.7 (C-12), 28.2 (C-16), 27.4 (C-23), 24.5 (C-6 and C-28), 24.1 (C-30), 22.0 (C-18), 21.6 (C-29), 18.3 (C-21 and C-11), 17.0 (C-26), 12.8 (C-19). 


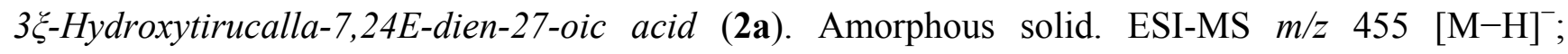

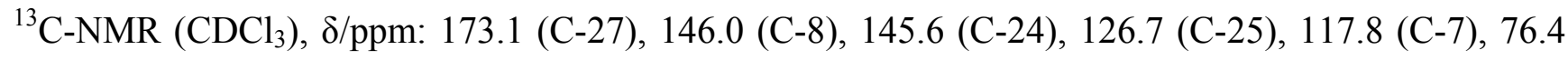
(C-3), 52.2 (C-17), 51.6 (C-14), 48.6 (C-9), 44.5 (C-5), 43.9 (C-13), 37.4 (C-4), 36.4 (C-2), 36.1 (C-1), 36.0 (C-20), 35.6 (C-10), 35.0 (C-23), 34.7 (C-12), 34.0 (C-15), 28.2 (C-16), 27.4 (C-30), 26.0 (C-22), 24.5 (C-28), 24.3 (C-6), 21.9 (C-18), 21.6 (C-29), 18.5 (C-11), 18.1 (C-21), 12.7 (C-19), 11.9 (C-26).

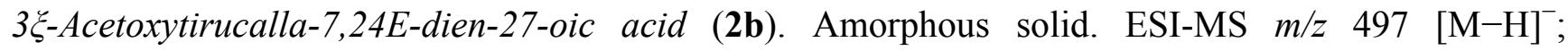
${ }^{13} \mathrm{C}-\mathrm{NMR}\left(\mathrm{CDCl}_{3}\right), \delta / \mathrm{ppm}: 171.1(\mathrm{C}-27), 171.0(\mathrm{C}=\mathrm{O}), 146.0(\mathrm{C}-24), 145.7(\mathrm{C}-8), 126.6$ (C-25), 117.7 (C-7), 81.1 (C-3), 52.8 (C-17), 51.2 (C-14), 50.7 (C-5 and C-9), 43.5 (C-13), 37.8 (C-4), 36.8 (C-20), 36.0 (C-1 and C-22), 34.8 (C-10), 34.6 (C-15), 33.9 (C-12), 28.2 (C-16), 27.2 (C-28), 27.0 (C-23), 24.2 (C-2), 23.7 (C-6), 21.8 (C-18 and C-30), 21.4 (C-29), 21.0 (Me), 18.2 (C-21 and C-11), 13.1 (C-19), 11.9 (C-26).

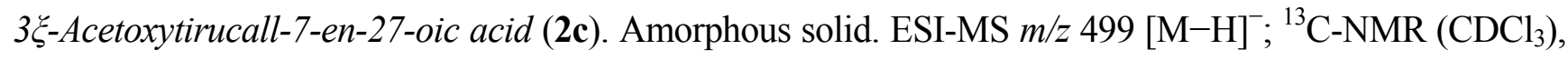

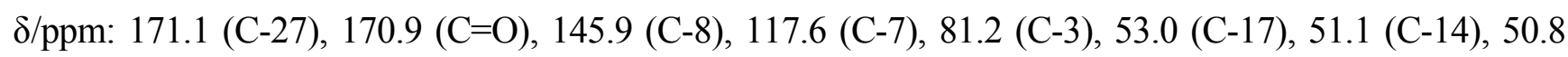
(C-5 and C-9), 43.5 (C-13), 37.8 (C-4 and C-25), 36.0 (C-1 and C-20), 35.9 (C-24), 34.8 (C-10 and C-22), 34.7 (C-15), 34.0 (C-12), 28.2 (C-16), 27.4 (C-28), 27.3 (C-23), 24.2 (C-2), 23.8 (C-6), 21.9 (C-18), 21.4 (C-29), $21.0(\mathrm{Me}), 18.3$ (C-11), 18.1 (C-21 and C-30), 17.0 (C-26), 13.1 (C-19).

Methyl 3-oxotirucalla-7,24E-dien-27-oate (2d). Amorphous solid. ESI-MS $m / z 467[\mathrm{M}-\mathrm{H}]^{-} ;{ }^{13} \mathrm{C}-\mathrm{NMR}$

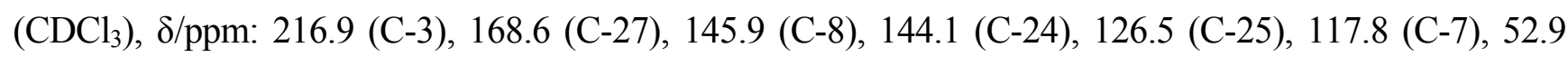
(C-5), 52.8 (OMe), 52.3 (C-17), 51.2 (C-14), 48.5 (C-9), 47.9 (C-4), 43.5 (C-13), 38.5 (C-1), 36.0 (C-20), 35.7 (C-23), 35.0 (C-10), 34.9 (C-2), 34.1 (C-15), 33.6 (C-12), 28.2 (C-16), 26.7 (C-22), 27.4 (C-30), 24.5 (C-28), 24.4 (C-6), 22.0 (C-18), 21.6 (C-29), 18.3 (C-21), 18.2 (C-11), 12.8 (C-19 and C-26).

Methyl 3 $\alpha$-hydroxytirucalla-7,24Z-dien-27-oate (3a). Amorphous solid. ESI-MS m/z 469 [M-H]'; ${ }^{13} \mathrm{C}-\mathrm{NMR}\left(\mathrm{CDCl}_{3}\right), \delta / \mathrm{ppm}: 168.6$ (C-27), 145.8 (C-8), 144.1 (C-24), 126.4 (C-25), 117.8 (C-7), 79.3 (C-3), 52.9 (C-5), 52.2 (OMe), 51.1 (C-14), 50.6 (C-17), 48.9 (C-9), 43.6 (C-13), 37.2 (C-4), 36.1 (C-1), 35.7 (C-10 and C-20), 35.6 (C-23), 34.9 (C-2 and C-12), 34.0 (C-15), 28.2 (C-16), 27.7 (C-28), 27.3 (C-30), 26.7 (C-22), 23.9 (C-6), 21.9 (C-18 and C-29), 20.7 (C-26), 18.2 (C-11), 18.1 (C-21), 13.1 (C-19).

Methyl $3 \alpha$-acetoxytirucalla-7,24Z-dien-27-oate (3b). Amorphous solid. ESI-MS m/z $513[\mathrm{M}-\mathrm{H}]^{-}$; ${ }^{13} \mathrm{C}-\mathrm{NMR}\left(\mathrm{CDCl}_{3}\right), \delta / \mathrm{ppm}: 171.0(\mathrm{C}-27), 168.6(\mathrm{C}=\mathrm{O}), 145.9(\mathrm{C}-8), 144.1(\mathrm{C}-24), 126.4(\mathrm{C}-25)$, 117.6 (C-7), 81.1 (C-3), 52.9 (C-5), 52.8 (OMe), 51.2 (C-17 and C-14), 48.8 (C-9), 47.6 (C-4), 43.5 (C-13), 38.1 (C-1), 36.0 (C-20), 35.7 (C-23), 34.8 (C-10 and C-2), 34.0 (C-15), 33.7 (C-12), 28.2 (C-16), 27.6 (C-30), 26.7 (C-22), 24.2 (C-6 and C-28), 21.9 (C-18), 21.3 (C-29), 20.7 (C-26), 20.1 (Me), 18.2 (C-11), 18.1 (C-21), 13.1 (C-19).

\subsection{Bioassay Procedures}

BALB/c mice and Golden hamsters (Mesocricetus auratus) were supplied by the animal breeding facility at the Instituto Adolfo Lutz, São Paulo, Brazil and maintained in sterilized cages under a controlled environment, receiving water and food ad libitum. Animal procedures were performed with 
the approval of the Research Ethics Commission, in agreement with the Guide for the Care and Use of Laboratory Animals from the National Academy of Sciences.

\subsection{Parasite Maintenance}

Isolated promastigotes of L. (L.) infantum (MHOM/BR/1972/LD) were maintained in M-199 medium supplemented with $10 \%$ fetal bovine serum (FBS) and $0.25 \%$ hemin at $24{ }^{\circ} \mathrm{C}$. L. infantum was maintained in golden hamsters up to 60-70 days post-infection. Amastigotes were harvested from spleens of infected hamsters by differential centrifugation [30]. T. cruzi trypomastigotes (Y strain) were maintained in LLC-MK2 (ATCC CCL 7) cells using RPMI-1640 medium supplemented with 2\% FBS at $37{ }^{\circ} \mathrm{C} 5 \% \mathrm{CO}_{2}$-humidified incubator [21].

\subsection{Mammalian Cells}

Peritoneal macrophages were collected from the peritoneal cavity of female BALB/c mice by washing with RPMI-1640 without phenol red, supplemented with 10\% FBS. NCTC (clone 929) cells were maintained in RPMI-1640 (without phenol red and supplemented with $10 \% \mathrm{FBS}$ ) at $37{ }^{\circ} \mathrm{C}$ in a humidified atmosphere containing $5 \% \mathrm{CO}_{2}[31]$.

\subsection{Determination of the Activity Against L. infantum-Promastigotes.}

To determine the $50 \%$ inhibitory concentration $\left(\mathrm{IC}_{50}\right)$ against $L$. infantum promastigotes, compounds 1-3, 1a-c, 2a-d, 3a, and 3b were previously dissolved in dimethyl sulphoxide (DMSO) and diluted with M-199 medium in 96-well microplates. Promastigotes were counted in a Neubauer hemocytometer and seeded at $1 \times 10^{6} /$ well with a final volume of $150 \mu \mathrm{L}$. The tested compounds were incubated in a range concentration of 100 to $0.78 \mu \mathrm{g} / \mathrm{mL}$ for $48 \mathrm{~h}$ at $24{ }^{\circ} \mathrm{C}$. The viability of promastigotes was verified by motility and morphology using light microscopy and by the colorimetric MTT assay [32]. Briefly, 3-[4,5-dimethylthiazol-2-yl]-2,5-diphenyltetrazolium bromide (MTT, $5 \mathrm{mg} / \mathrm{mL}$ ) was dissolved in phosphate-buffered saline (PBS), sterilized through $0.22 \mu \mathrm{m}$ membranes and added, $20 \mu \mathrm{L} /$ well, for $4 \mathrm{~h}$ at $24{ }^{\circ} \mathrm{C}$. Formazan extraction was performed using $10 \%$ sodium dodecyl sulfate (SDS) for $18 \mathrm{~h}$ $\left(80 \mu \mathrm{L} /\right.$ well) at $24{ }^{\circ} \mathrm{C}$ and the optical density (OD) was determined in a spectrophotometric plate reader Filter Max 5 (Molecular Devices, Sunnyvale, CA, USA) at $570 \mathrm{~nm}$. Promastigotes incubated without compounds or DMSO were used as control (100\% viability) and wells without cells as blank. Controls with DMSO and without drugs were also performed. Miltefosine was used as a standard drug. We selected the maximal tested concentration of $100 \mu \mathrm{g} / \mathrm{mL}$ for all antiparasitic assays and those compounds with $\mathrm{IC}_{50}$ values lower than $100 \mu \mathrm{g} / \mathrm{mL}$ were considered not active [33].

\subsection{Determination of the Activity Against L. infantum-Intracellular Amastigotes}

Peritoneal macrophages were obtained as described previously and $L$. infantum amastigotes were obtained from spleens of infected hamsters by differential centrifugation. Peritoneal macrophages were seeded at $1 \times 10^{5}$ cells per well in Nunc ${ }^{\mathrm{TM}}$ 16-well slide chambers (Aldrich, St. Louis, MO, USA) for $24 \mathrm{~h}$ at $37{ }^{\circ} \mathrm{C}$ in a $5 \% \mathrm{CO}_{2}$-humidified incubator. Amastigotes were added to macrophages at 10:1 ratio (amastigotes:macrophage) and incubated for $24 \mathrm{~h}$. Non-internalized parasites were 
removed by washing twice with medium and the cells were then incubated with compounds in a range concentration of 100 to $0.78 \mu \mathrm{g} / \mathrm{mL}$ for $120 \mathrm{~h}$ at $37{ }^{\circ} \mathrm{C}$ in $5 \% \mathrm{CO}_{2}$, using miltefosine as standard drug. At the end of the assay, the cells were fixed in methanol, stained with Giemsa and observed under a light microscope to determine the number of infected macrophages out of 400 cells [33].

\subsection{Determination of the Activity Against Trypanosoma cruzi-Trypomastigotes}

Compounds 1-3, 1a-c, 2a-d, 3a, and 3b were dissolved in DMSO and diluted in RPMI-1640 medium to determine the $50 \%$ inhibitory concentration $\left(\mathrm{IC}_{50}\right)$ as described above for the antileishmanial assay. Free trypomastigotes obtained from LLC-MK2 cultures were counted in a Neubauer hemocytometer and seeded at $1 \times 10^{6} /$ well in 96-well microplates. The tested compounds were incubated in a range concentration of 100 to $0.78 \mu \mathrm{g} / \mathrm{mL}$ for $24 \mathrm{~h}$ at $37{ }^{\circ} \mathrm{C}$ in a $5 \% \mathrm{CO}_{2}$ humidified incubator, using benznidazole as standard drug. The viability of the trypomastigotes was verified by the MTT assay as described above [34,35].

\subsection{Determination of the Cytotoxicity Against Mammalian Cells}

The $50 \%$ cytotoxic concentration $\left(\mathrm{CC}_{50}\right)$ was determined in NCTC clone 929 cells. NCTC cells were seeded at $6 \times 10^{4}$ cells/well in 96 -well microplates at $37{ }^{\circ} \mathrm{C}$ in a $5 \% \mathrm{CO}_{2}$. The mammalian cells were incubated with tested compounds to the highest concentration of $200 \mu \mathrm{g} / \mathrm{mL}$ for $48 \mathrm{~h}$ at $37{ }^{\circ} \mathrm{C}$, using miltefosine as standard drug. The viability of the cells was determined by MTT assay at $570 \mathrm{~nm}$ [36]. The selectivity index (SI) was determined considering the following equation: $\mathrm{CC}_{50} \mathrm{NCTC}$ cells/ $/ \mathrm{IC}_{50}$ parasites.

\subsection{Statistical Analysis}

The data obtained represent the mean and standard deviation of duplicate samples from at least three independent assays. The $\mathrm{IC}_{50}$ and $\mathrm{CC}_{50}$ values were calculated using sigmoid dose-response curves in Graph Pad Prism 5.0 software (GraphPad Software, San Diego, CA, USA).

\subsection{Molecular Interaction Fields (MIF)}

The structures were drawn using the Marvin Sketch v. 6.1.4 [37], and the three dimensional structures (3D) were generated using the software Standardizer v 6.1.4. [37]. The 3D structures were used as the initial structures to generate molecular descriptors employing the VolSurf $+\mathrm{v}$ 1.0.7 program [27]. The descriptors were generated using the following probes N1 (amide nitrogen-hydrogen bond donor probe), $\mathrm{O}$ (carbonyl oxygen-hydrogen bond acceptor probe), OH2 (water probe), and DRY (hydrophobic probe) [27], and other non MIF-derived descriptors, totalizing 128 descriptors.

\subsection{Decision Tree}

Knime 2.7.1 software (KNIME 2.7.1 the Konstanz Information Miner Copyright, 2003-2013) [38] was used to perform all the analyses described hereafter. The descriptors and class variables were imported from Volsurf + v.1.0.7 program. For internal validation we used cross-validation by the leave-one-out method, using the decision tree learning J48 (C4.5 decision tree) [28]. The compounds without activity at 
$100 \mu \mathrm{g} / \mathrm{mL}$ were classified as inactive and the remaining as active. Decision trees arrange a subset of descriptor components in a hierarchical fashion (a binary tree) such that on a particular node in the tree, a classification on a single component decides whether the left or the right branch underneath is followed. Decision trees provide both rules, and the means to associate specific molecular features/descriptors. The following optimal parameters were used: confidence factor $=0.25$; minimal number of objects $=2$; number of folds $=3$; and seed $=1$.

\section{Conclusions}

The results presented herein indicate that natural tirucallane triterpenoids $\mathbf{1}-\mathbf{3}$ could be used as new prototypes for drug design studies against leishmaniasis and Chagas' disease. Additionally, some important relationships between chemical structure and biological activity of these compounds could be established since several derivatives (compounds $\mathbf{1 a}-\mathbf{c}, \mathbf{2 a}-\mathbf{d}, \mathbf{3 a}$ and $\mathbf{3 b}$ ) were prepared and assayed. The obtained data suggest that the presence of carbonyl or hydroxyl at C-3, and double bond between C-24 and C-25 with carboxylic acid at C-27 are crucial to the antileishmanial activity, while the carbonyl group at C-3 combined with a double bond ( $Z$ configuration) between $\mathrm{C}-24$ and $\mathrm{C}-25$, or with an ester group at C-27, or without a double bond between C-24 and C-25 cause reduction in antitrypanosomal activity. Therefore, complementary studies aiming at the determination of mechanism of action of the most active compounds 1, 2, 2a and 3 should be conducted.

\section{Acknowledgments}

The authors would like to thank the CNPq (300546/2012-2 and 471458/2012-0), FAPESP (2011/51739-0, 2012/18756-1 and 2013/16320-4) and FAPEMIG for providing financial support and fellowships. The authors are grateful to Diogo Oliveira-Silva (UNIFESP) for the ESI-MS measurements. This publication is part of the activities of the Research Network Natural Products against Neglected Diseases (ResNetNPND): http://www.uni-muenster.de/ResNetNPND/.

\section{Author Contributions}

Conceived and designed the experiments: AGT, MTS, JHGL. Performed the experiments: TRM, TACS, AGT, SETB, MTS, RMFS, ACCA, AO, JHGL. Analyzed the data: TRM, TACS, AGT, SETB, MTS, RMFS, AO, SALM, PS, JHGL. Contributed reagents/materials/analysis tools: AGT, SETB, MTS, AO, SALM, PS, JHGL. Wrote the paper: AGT, MTS, JHGL.

\section{Conflicts of Interest}

The authors declare no conflict of interest.

\section{References}

1. Corrêa, M.P. Dicionário de Plantas Úteis do Brasil e das Exóticas Cultivadas; Imprensa Nacional: Rio de Janeiro, Brazil, 1984; Volume 1, p. 311.

2. Lorenzi, H. Árvores Brasileiras: Manual de Identificação e Cultivo de Plantas Arbóreas Nativas do Brasil; Plantarum: São Paulo, Brazil, 1992; p. 384. 
3. Morton, J.F. Brazilian pepper-its impact on people, animals and the environment. Econ. Bot. 1978, 32, 353-359.

4. Schmourlo, G.; Mendonça-Filho, R.R.; Alviano, C.S.; Costa, S.S. Screening of antifungal agents using ethanol precipitation and bioautography of medicinal and food plants. J. Ethnopharmacol. 2005, 96, 563-568.

5. Jain, M.K.; Yu, B.Z.; Rogers, J.M.; Smith, A.E.; Boger, E.T.A.; Ostrander, R.L.; Rheingold, A.L. Specific competitive inhibitor of secreted phospholipase A2 from berries of Schinus terebinthifolius. Phytochemistry 1995, 39, 537-547.

6. Johann, S.; Sá, N.P.; Lima, L.A.R.S.; Cisalpino, P.S.; Costa, B.B.; Alves, T.M.A.; Siqueira, E.P.; Zani, C.L. Antifungal activity of schinol and a new biphenyl compound isolated from Schinus terebinthifolius against the pathogenic fungus Paracoccidioides brasiliensis. Ann. Clin. Microbiol. Antimicrob. 2010, 9, 30-35.

7. Ceruks, M.; Romoff, P.; Fávero, O.A.; Lago, J.H.G. Constituintes fenólicos polares de Schinus terebinthifolius Raddi (Anacardiaceae). Quim. Nova 2007, 30, 597-599.

8. Santana, J.S.; Sartorelli, P.; Lago, J.H.G.; Matsuo, A.L. Isolamento e avaliação do potencial citotóxico de derivados fenólicos de Schinus terebinthifolius Raddi (Anacardiaceae). Quim. Nova 2012, 35, 2245-2248.

9. Lima, M.R.F.; Luna, J.S.; Santos, A.F.; Andrade, M.C.C.; Sant'ana, A.E.G.; Genet, J.P.; Marquez, B.; Neuville, L.; Moreau, N. Anti-bacterial activity of some Brazilian medicinal plants. J. Ethnopharmacol. 2006, 105, 137-147.

10. Ibrahim, M.T.; Fobbe, R.; Nolte; J. Chemical composition and biological studies of Egyptian Schinus molle L. and Schinus terebinthifolius Raddi oils. Bull. Fac. Pharm. 2004, 42, 289-296.

11. Singh, A.K.; Singh, A.K.; Gupta, K.C.; Brophy, J.J. Essential oil of leaves and inflorescence of Schinus terebinthifolius: An exotic plant of India. J. Essent. Oil Res.1998, 10, 697-699.

12. Barbosa, L.C.A.; Demuner, A.J.; Clemente, A.D.; Paula, V.F.; Ismail, F.M.D. Seasonal variation in the composition of volatile oils from Schinus terebinthifolius Raddi. Quim. Nova 2007, 30, 1959-1965.

13. Bendaoud, H.; Romdhane, M.; Souchard, J.P.; Cazaux, S.; Bouajila, J. Chemical composition and anticancer and antioxidant activities of Schinus molle L. and Schinus terebinthifolius Raddi berries essential oils. J. Food Sci. 2010, 75, C466-C472.

14. Sartorelli, P.; Santana, J.S.; Guadagnin, R.C.; Lago, J.H.G.; Pinto, E.G.; Tempone, A.G.; Stefani, H.A.; Soares, M.G.; Silva, A.M. In vitro trypanocidal evaluation of pinane derivatives from essential oils of ripe fruits from Schinus terebinthifolius Raddi (Anacardiaceae). Quim. Nova 2012, 35, 743-747.

15. Santana, J.S.; Sartorelli, P.; Guadagnin, R.C.; Matsuo, A.L.; Figueiredo, C.R.; Soares, M.G.; Zanin, J.L.B.; Silva, A.M.; Lago, J.H.G. Essential oils from Schinus terebinthifolius leaves chemical composition and in vitro cytotoxicity evaluation. Pharm. Biol. 2012, 50, 1248-1253.

16. Moura-Costa, G.F.; Nocchi, S.R.; Ceole, L.F.; de Mello, J.C.; Nakamura, C.V.; Dias-Filho, B.P.; Temponi, L.G.; Ueda-Nakamura, T. Antimicrobial activity of plants used as medicinal on an indigenous reserve in Rio das Cobras, Paraná, Brazil. J. Ethnopharmacol. 2012, 28, 143, 631-638. 
17. Abdel-Sattar, E.; Maes, L.; Salama, M.M. In vitro activities of plant extracts from Saudi Arabia against malaria, leishmaniasis, sleeping sickness and Chagas disease. Phytother. Res. 2010, 24, 1322-1328.

18. Barrett, M.P.; Croft, S.L. Management of trypanosomiasis and leishmaniasis. Br. Med. Bull. 2012, 104, 175-196.

19. Palavani, E.B.; Mariane, B.; Vallim M.A.; Pascon R.C.; Sartorelli, P.; Soares, M.G.; Lago, J.H.G. The seasonal variation if the chemical composition of essential oils from Porcelia macrocarpa R.E. Fries (Annonaceae) and their antimicrobial activity. Molecules 2013, 18, 13574-13587.

20. Bou, D.D.; Lago, J.H.G.; Figueiredo, C.R.; Matsuo, A.L.; Guadagnin, R.C.; Soares, M.G.; Sartorelli, P. Chemical composition and cytotoxicity evaluation of essential oil from leaves of Casearia sylvestris, its main compound $\alpha$-zingiberene and derivatives. Molecules 2013, 18 , 9477-9487.

21. Rea, A.; Tempone, A.G.; Pinto, E.G.; Mesquita, J.T.; Silva, L.G.; Rodrigues, E.; Sartorelli, P.; Lago, J.H.G. Soulamarin isolated from Calophyllum brasiliense (Clusiaceae) induces plasma membrane permeabilization of Trypanosoma cruzi and mitochondrial dysfunction. PLoS Negl. Trop. Dis. 2013, 7, e2556-e2563.

22. Yamamoto, E.S.; Campos, B.L.S.; Laurenti, M.D.; Lago, J.H.G.; Grecco, S.S.; Corbett, C.E.P.; Passero, L.F.D. Treatment with triterpenic fraction purified from Baccharis uncinella leaves inhibits Leishmania (Leishmania) amazonensis spreading and improves Th1 immune response in infected mice. Parasitol. Res. 2014, 113, 333-339.

23. Mulholland, D.A.; Nair, J.J. Triterpenes from Dysoxylum pettigrewianum. Phytochemistry 1994, $37,1409-1411$.

24. Department of health and human services food and drug administration. Guidance for industry antiviral product development-conducting and submitting Virology-studies to the agency. Available online: http://www.fda.gov/OHRMS/DOCKETS/98fr/05d-0183-gdl0002-01.pdf (accessed on 17th April 2014).

25. Reimão, J.Q.; Scotti, M.T.; Tempone, A.G. Anti-leishmanial and anti-trypanosomal activities of 1,4-dihydropyridines: In vitro evaluation and structure-activity relationship study. Bioorg. Med. Chem. 2010, 18, 8044-8053.

26. Murray, H.W.; Delph-Etienne, S. Roles of endogenous gamma interferon and macrophage microbicidal mechanisms in host response to chemotherapy in experimental visceral leishmaniasis. Infect. Immun. 2000, 68, 288-293.

27. Mesquita, J.T.; Costa-Silva, T.A.; Borborema, S.E.; Tempone, A.G. Activity of imidazole compounds on Leishmania (L.) infantum chagasi: Reactive oxygen species induced by econazole. Mol. Cell. Biochem. 2014, 389, 293-300.

28. Cruciani, G.; Crivori, P.; Carrupt P.A.; Testa, B. Molecular fields in quantitative structure-permeation relationships: The VolSurf approach. J. Mol. Struc-Theochem. 2000, 503, 17-30.

29. Quinlan, J.R. C4.5: Programs for Machine Learning, 1st ed.; Morgan Kaufmann Publishers: London, UK, 1993; p. 302.

30. Stauber, L.A.; Franchino, E.M.; Grun, J. An eight-day method for screening compounds against Leishmania donovani in golden hamsters. J. Protozool. 1985, 5, 269-273. 
31. Corrêa, D.S.; Tempone, A.G.; Reimão, J.Q.; Taniwaki, N.N.; Romoff, P.; Fávero, O.A.; Sartorelli, P.; Mecchi, M.C.; Lago, J.H.G. Anti-leishmanial and anti-trypanosomal potential of polygodial isolated from stem barks of Drimys brasiliensis Miers (Winteraceae). Parasitol. Res. 2011, 109, 231-236.

32. Tempone, A.G.; Pimenta, D.C.; Lebrun, I.; Sartorelli, P.; Taniwaki, N.N.; Andrade, H.F., Jr.; Antoniazzi, M.M; Jared, C. Antileishmanial and antitrypanosomal activity of bufadienolides isolated from the toad Rhinella jimi parotoid macrogland secretion. Toxicon 2008, 52, 13-21.

33. Tempone, A.G.; Oliveira, C.M.; Berlinck, R.G.S. Current approaches to discover marine antileishmanial natural products. Planta Med. 2011, 77, 572-585.

34. Tada, H.; Shiho, O.; Kuroshima, K.; Koyama, M.; Tsukamoto, K. An improved colorimetric assay for interleukin 2. J. Immunol. Methods 1986, 93, 157-165.

35. Lane, J.E.; Ribeiro-Rodrigues, R.; Suarez, C.C.; Bogitsh, B.J.; Jones, M.M.; Singh, P.K.; Carter, C.E. In vitro trypanocidal activity of tetraethylthiuram disulfide and sodium diethylamine- $N$ carbodithioate on Trypanosoma cruzi. Am. J. Trop. Med. Hyg. 1996, 55, 263-266.

36. Oliveira, A.; Mesquita, J.T.; Tempone, A.G.; Lago, J.H.G.; Guimarães, E.F.; Kato, M.J. Leishmanicidal activity of an alkenylphenol from Piper malacophyllum is related to plasma membrane disruption. Exp. Parasitol. 2012, 132, 383-387.

37. ChemAxon-cheminformatic platforms and desktop applications. Available online: http://www.chemaxon.com (accessed on 30 April 2014)

38. Knime-Konstanz Information Miner. Available on line: http://www.knime.org (accessed on 30 April 2014)

Sample Availability: Samples of compounds 1-3, 1a-c, 2a-d, 3a, and $\mathbf{3 b}$ are available from the authors.

(C) 2014 by the authors; licensee MDPI, Basel, Switzerland. This article is an open access article distributed under the terms and conditions of the Creative Commons Attribution license (http://creativecommons.org/licenses/by/3.0/). 